\title{
ANALISIS SPASIAL SEBARAN LAHAN KRITIS DI KPHP UNIT XII BATANGHARI PROVINSI JAMBI
}

\author{
Spatial Analysis of Critical Land at KPHP Unit XII Batanghari Jambi Province \\ Eva Achmad*1), Agus Kurniawan Mastur²), dan Yunita Lestari ${ }^{1)}$ \\ ${ }^{1)}$ Program Studi Kehutanan Fakultas Pertanian Universitas Jambi \\ 2)Program Studi Agroekoteknologi Fakultas Pertanian Universitas Jambi \\ *Email : evaachmad@unja.ac.id
}

Diterima: 26/02/2021, Direvisi: 14/07/2021, Disetujui: 16/07/2021

\begin{abstract}
Critical land occured as a result of land cover changes from vegetated into non vegetated land or the composition of the vegetation has changed. This study aimed to analyze the distribution of land critical at KPHP Unit XII Batanghari. Critical land analysis was based on the Perdirjen PDASHL Number P.3/PDASHL/SET/KUM.1/7/2018. Land is classified into 5 levels of criticality, namely: non-critical, critical potential, somewhat critical, critical and very critical. The parameters used in determining the level of criticality of the land are: land cover, erosion-prone class, slope class and the presence of land inside or outside the forest function. Spatial analysis used by Geographic Information System (GIS) and remote sensing technology. GIS is able to analyze and represent geographic phenomenon. Landsat 8 imagery was analyzed to obtain land cover clasification. The results of the analysis showed that critical land level of KPHP Unit XI Batanghari consisted of 3,609 ha (4.45\%) that classified as very critical and 3,599 ha (4,43\%) as critical land. Then, land with a somewhat critical level had the largest area, namely 26,024 ha or $32.07 \%$ of the total area of KPHP Unit XII Batanghari. The landcover was the main parameter to determine the level of criticality of the land. The openland cover type had the maximum score 60 .
\end{abstract}

Keywords: critical land; landcover; GIS

\section{ABSTRAK}

Lahan kritis terjadi sebagai akibat dari perubahan penutupan lahan dari bervegetasi menjadi tidak bervegetasi atau komposisi vegetasi telah berubah. Penelitian ini bertujuan untuk menganalisis sebaran tingkat kekritisan lahan di KPHP Unit XII Batanghari. Analisis tingkat kekritisan lahan berpedoman pada Perdirjen PDASHL Nomor P.3/PDASHL/SET/KUM.1/7/2018. Lahan diklasifikasikan kedalam 5 tingkat kekritisan yaitu: tidak kritis, potensial kritis, agak kritis, kritis dan sangat kritis. Parameter yang digunakan dalam penentuan tingkat kekritisan lahan yaitu: kelas penutupan lahan, kelas rawan erosi, kelas lereng dan keberadaan lahan didalam atau diluar kawasan hutan. Analisis spasial menggunakan teknologi Sistem Informasi Geografis (SIG) dan penginderaan jauh. SIG mampu menganalis dan merepresentasikan fenomena secara geografis. Citra Landsat 8 digunakan sebagai sumber data penutupan lahan. Hasil analisis menunjukkan bahwa terdapat lahan dengan tingkat kekritisan sangat kritis dan kritis masing-masing seluas 3.609 ha $(4,45 \%)$ dan seluas 3.599 ha $(4,43 \%)$ di KPHP Unit XII Batanghari. Lahan dengan tingkat agak kritis memiliki luasan terbesar yaitu seluas 26.024 ha 
atau 32,07\% dari luas KPHP Unit XII Batanghari. Penutupan lahan dengan skor maksimal 60 pada lahan terbuka merupakan parameter utama dan penentu tingkat kekritisan lahan.

Kata Kunci: lahan kritis; penutupan lahan; SIG

\section{PENDAHULUAN}

Lahan sebagai sumberdaya alam berperan penting untuk memenuhi kebutuhan hidup manusia (Prabandaru, 2016). Pertumbuhan penduduk berdampak pada meningkatnya kebutuhan manusia dan dibutuhkan lahan dalam jumlah yang luas (Kusumandari dan Nugroho, 2015). Eksploitasi lahan dilakukan sebagai konsekuensi pemenuhan kebutuhan hidup. Alih fungsi lahan merupakan bentuk nyata dari pemanfaatan lahan yang berdampak pada berubahnya tatanan ekosistem dari suatu penggunaan tertentu. Di sisi lain, pemanfaatan lahan yang tidak sesuai dengan kemampuan lahan dapat berdampak pada penurunan kualitas lahan seperti menurunnya produktivitas lahan. Aktivitas-aktivitas pemanfaatan lahan yang tidak mempertimbangkan kaidah konservasi tanah dan air merupakan penyebab lahan terdegradasi dan pada akhirnya menimbulkan lahan kritis (Nugroho dan Prayogo, 2008; Rosyada et al., 2015; Kubangun et al., 2016).

Lahan kritis adalah lahan yang sudah tidak produktif sebagai dampak dari pengelolaan yang tidak memperhatikan konservasi tanah dan air (Sunartomo, 2011; Suriani, 2019), yang mengalami proses kerusakan fisik, kimia dan biologi karena penggunaan yang tidak sesuai kemampuan (Auliana et al., 2017; Makalalag et al., 2020). Lahan kritis terjadi sebagai akibat dari perubahan penggunaan lahan dari hutan atau lahan pertanian menjadi non pertanian atau lahan terbangun, sehingga kawasan yang berfungsi sebagai daerah resapan air menjadi berkurang (Achmad et al., 2020). Dampak berikutnya yaitu menyebabkan kekeringan pada musim kemarau dan banjir atau longsor pada musim hujan (Ramayanti, 2015; Ruhama, 2020). Proses terjadinya lahan kritis dimana air hujan yang jatuh ke permukaan bumi menyebabkan erosi dan menghancurkan permukaan tanah dengan penutupan lahan yang telah rusak (Mulyadi dan Jupri, 2016).

Data dari Kementerian Lingkungan Hidup dan Kehutanan, tahun 2018 deforestasi di Provinsi Jambi seluas 9.236 ha, dalam kawasan hutan seluas 6.048 ha yang sebagaian besar terdapat di Hutan Produksi Terbatas seluas 3.514 ha. Berdasarkan Keputusan Menteri Lingkungan Hidup dan Kehutanan Nomor SK.306/MENLHK/PDASHL/DAS.0/7/2018 tentang Penetapan Lahan Kritis Nasional, bahwa luas lahan kritis nasional tahun 2018 sebesar 14 juta ha dan sebesar 213.985 ha terletak di Provinsi Jambi. Kementerian Lingkungan Hidup dan Kehutanan telah melakukan perbaikan kondisi lahan kritis yaitu menurunkan dan mengurangi luasan lahan kritis dengan kegiatan rehabilitasi di Wilayah Kesatuan Peneglolaan Hutan (KPH) berdasarkan Rencana Strategis 2015-2019.

Kesatuan Pengelolaan Hutan Produksi (KPHP) Unit XII Batanghari merupakan salah satu $\mathrm{KPH}$ yang berada di Provinsi Jambi. KPHP Unit XII Batanghari terbagi atas Izin Usaha Pemanfaatan Hasil Hutan Kayu-Restorasi Ekosistem (IUPHHK-RE) seluas 39.183 ha (48,29\%), Izin Usaha Pemanfaatan Hasil Hutan Kayu-Hutan Tanaman (IUPHHK-HT) seluas 28.608 ha $(35,26 \%)$, Izin Hutan Desa (HD) seluas 3.548 ha $(4,37 \%)$ dan Izin Hutan Tanaman Rakyat (HTR) seluas 6.540 ha $(8,06 \%)$. Beberapa penutupan lahan yang terdapa di KPHP Unit XII Batanghari yaitu : hutan sekunder seluas 23.601 ha $(29,09 \%)$, pertanian lahan kering campur 
semak seluas 22.805 ha $(28,11 \%)$, perkebunan seluas 15.093 ha $(18,60 \%)$ dan semak belukar seluas 12.369 ha (15,26\%) (KPHP Unit XII Batanghari, 2016).

Beragam izin pemanfaatan yang terdapat dalam kawasan akan berpengaruh pada model pengelolaan yang berimplikasi pada ekosistem hutan. Menurut Bozali (2020), ekosistem hutan berperan penting dalam penyediaan jasa ekosistem termasuk mitigasi bencana erosi. Erosi merupakan dampak paling buruk dari degradasi lahan dengan konsekuensi gangguan lingkungan dan social ekonomi. (Kebede et al., 2021).

Berdasarkan data diatas, dapat dijelaskan bahwa tidak semua kawasan KPHP Unit XII Batanghari memiliki penutupan lahan hutan. Tutupan lahan pertanian lahan kering, perkebunan dan semak belukar memiliki pola kerapatan vegetasi yang berbeda dengan hutan, sehingga kemampuan untuk menahan daya rusak dari butiran hujan juga berbeda. Hal ini dapat menimbulkan terjadinya lahan kritis jika tidak dikelola dengan tepat. Kondisi penutupan lahan sangat mempengaruhi terjadinya lahan kritis. Menurut Nasihin et al., (2016) bahwa tutupan lahan merupakan wujud fisik suatu lahan yang menggambarkan status ekologisnya dan bisa berubah jika ada intervensi manusia, gangguan alam serta suksesi.

Informasi sebaran dan tingkat kekritisan lahan sangat diperlukan dalam upaya pengelolaan kawasan. Penyediaan data dan informasi tersebut diperlukan terutama dalam menunjang perencanaan rehabilitasi. Data lahan kritis tahun 2018 telah tersedia, namun kajian tingkat kekritisan lahan di KPHP Unit XII Batanghari dengan kondisi tutupan lahan terbaru belum dilakukan. Kondisi tutupan lahan eksisting sangat berperan penting dalam penentuan sebaran lahan kritis. Selain tutupan lahan yang bersifat dinamis, data lereng, bahaya erosi dan fungsi kawasan juga menjadi penentu dalam tingkat kekritisan lahan.

Pemetaan lahan kritis dapat dilakukan dengan menggunakan Teknologi Penginderaan Jauh dan Sistem Informasi Geografis (SIG). Penginderaan jauh merupakan teknik yang relevan dalam pengumpulan data spasial tanpa pengukuran lapangan secara langsung (Suntoro, 2019; Pijl et al., 2020). SIG memiliki kemampuan dalam menganalisis dan mensimulasikan berbagai fenomena spasial (Tavana, 2016; Anasiru, 2016; Majid dan Mir, 2021). Berdasarkan uraian diatas, perlu dilakukan kajian analisis tingkat kekritisan lahan di KPHP Unit XII Batanghari. Tujuan penelitian ini adalah mengidentifikasi sebaran spasial dan luasan lahan kritis sebagai rujukan dalam penetapan areal prioritas perencanaan rehabilitasi

\section{METODE}

Penelitian dilaksanakan selama 3 bulan, yaitu pada bulan Oktober-Desember 2020. Lokasi penelitian di wilayah KPHP Unit XII Batanghari. Pengolahan dan analisis data dilakukan di Laboratorium Survey dan Evaluasi Lahan Fakultas Pertanian Universitas Jambi. Alat yang digunakan dalam penelitian ini adalah GPS (Global Positioning System), kamera digital, clinometer, kompas dan alat tulis. Bahan yang digunakan dalam penelitian ini yaitu : Citra Satelit Landsat 8 OLI path 125 row 61 dan 62, Peta Administrasi Kabupaten Batang Hari, Peta KPHP Unit XII Batanghari, Peta Erosi dan DEMNAS.

Penentuan tingkat dan sebaran lahan kritis berpedoman pada Peraturan Direktur Jenderal Pengendalian Daerah Aliran Sungai dan Hutan Lindung Nomor P.3/PDASHL/SET/KUM.1/7/2018 tentang Petunjuk Teknis Penyusunan Data Spasial Lahan Kritis. 4 parameter yang digunakan dalam analisis yaitu: tutupan lahan, kelas rawan erosi, fungsi kawasan dan peta lereng. Masing-masing parameter memiliki bobot yang berbeda. 
Penyusunan data, bobot dan skoring menggunakan SIG yang mampu menganalisis dan mengkombinasikan beberapa parameter tematik. Peta tutupan lahan diperoleh dari hasil analisis Citra Landsat 8, Peta Lereng diturunkan dari DEMNAS, sedangkan peta kelas rawan erosi dan peta fungsi kawasan bersumber dari Balai Pengelolaan Daerah Aliran Sungai dan Hutan Lindung (BPDASHL) Batanghari dan Peta Fungsi Kawasan dari KPHP Unit XII Batanghari.

Tabel 1. Jenis, kelas dan skor penutupan lahan

Table1. Type, class and land cover score

\begin{tabular}{|c|c|c|c|c|}
\hline Nomor & Simbol & Keterangan & Kelas & Skor \\
\hline 1 & Lanud & Airport & \multirow{12}{*}{1} & \multirow{12}{*}{12} \\
\hline 2 & A & Tubuh air & & \\
\hline 3 & Rw & Rawa & & \\
\hline 4 & S & Savana & & \\
\hline 5 & $\mathrm{Pm} / \mathrm{Tr}$ & Pemukiman/ Transmigrasi & & \\
\hline 6 & $\mathrm{Hp}$ & Hutan Lahan Kering Primer & & \\
\hline 7 & Sw & Sawah & & \\
\hline 8 & $\mathrm{Tm}$ & Tambak & & \\
\hline 9 & $\mathrm{Hmp}$ & Hutan Mangrove Primer & & \\
\hline 10 & $\mathrm{Hms}$ & Hutan Mangrove Sekunder & & \\
\hline 11 & Hrp & Hutan Rawa Primer & & \\
\hline 12 & Hrs & Hutan Rawa Sekunder & & \\
\hline 13 & $\mathrm{Hs}$ & Hutan Lahan Kering Sekunder & \multirow{2}{*}{2} & \multirow{2}{*}{24} \\
\hline 14 & $\mathrm{Ht}$ & Hutan Tanaman & & \\
\hline 15 & $\mathrm{Pk}$ & Perkebunan & 3 & 36 \\
\hline 16 & $B$ & Semak/ Belukar & \multirow{4}{*}{4} & \multirow{4}{*}{48} \\
\hline 17 & $\mathrm{Br}$ & Belukar Rawa & & \\
\hline 18 & $\mathrm{Pt}$ & Pertanian Lahan Kering & & \\
\hline 19 & $\mathrm{Pc}$ & Pertanian Lahan Campur & & \\
\hline 20 & $T$ & Tanah Terbuka & \multirow{2}{*}{5} & \multirow{2}{*}{60} \\
\hline 21 & $\mathrm{~Tb}$ & Pertambangan & & \\
\hline 22 & Aw & Awan & \multirow{2}{*}{0} & \multirow{2}{*}{0} \\
\hline 23 & TAD & Tidak Ada Data & & \\
\hline
\end{tabular}

Sumber : Perdirjen PDASHL Nomor P.3/PDASHL/SET/KUM.1/7/2018

Pelaksanaan penelitian terdiri dari beberapa tahapan, yaitu: persiapan, analisis dan interpretasi data. Pada tahap persiapan meliputi pengumpulan data-data penunjang dan studi literatur. Analisis data dilaksanakan dengan beberapa bagian antara lain: analisis tutupan lahan, analisis lereng, tingkat rawan erosi, analisis fungsi kawasan, analisis lahan kritis dan pembuatan peta lahan kritis. Tahap akhir yaitu interpretasi data dengan mendeskripsikan sebaran dan tingkat kekritisan lahan.

\section{Analisis Tutupan Lahan}

Tutupan lahan dianalisis berdasarkan Citra Landsat 8. Klasifikasi tutupan lahan dilakukan secara kualitatif (visual) dan kuantitatif (digital) menggunakan metode klasifikasi terbimbing. Hasil klasifikasi selanjutnya dilakukan grondcheck agar peta tutupan lahan menjadi akurat. Jenis penutupan lahan diperoleh dari Interpretasi Citra Landsat 8 merujuk pada Peraturan Direktorat Jenderal Planologi Kehutanan dan Tata Lingkungan yang membagi jenis penutupan lahan menjadi 23 jenis penutupan lahan (Tabel 1). Kelas penutupan lahan adalah 
penggolongan 5 kelas dari 23 jenis penutupan lahan untuk pemberian skor dan bobot penutupan lahan maksimum $60 \%$.

\section{Analisis Peta Rawan Erosi}

Peta rawan erosi terbagi menjadi 5 kelas dan diperoleh dari BPDASHL Batanghari. Pemberian skor didasarkan pada bobot maksimum yaitu 40 (Tabel 2). Groundcheck dilakukan untuk memverifikasi keadaan dilapangan.

Tabel 2. Skor kelas erosi

Table 2. Erosion class score

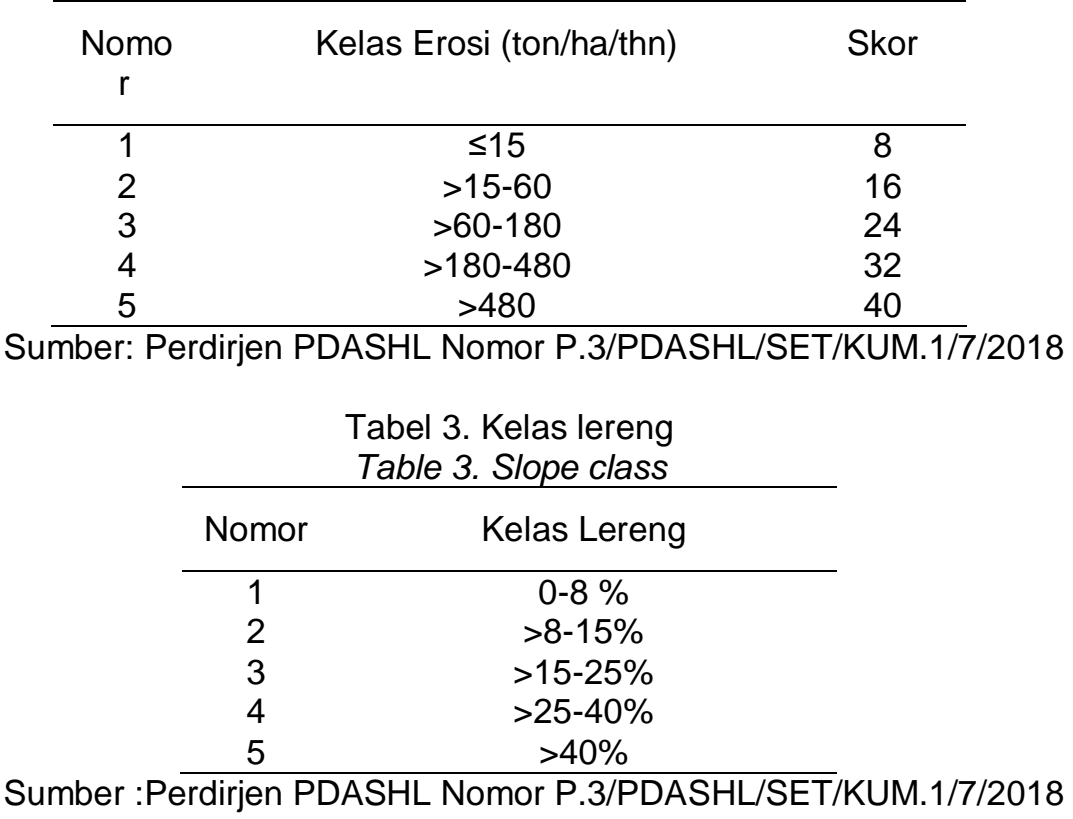

\section{Analisis Lereng}

Peta lereng dianalisis dan diturunkan dari DEMNAS. Deliniasi area berdasarkan batas lokasi penelitian yaitu KPHP Unit XII Batanghari. Dalam pembuatan peta lahan kritis, peta lereng merupakan parameter yang terbagi menjadi 5 kelas lereng dalam persen. Kelas lereng dan presentase kelasnya dapat dilihat pada Tabel 3.

\section{Analisis Fungsi Kawasan}

Jenis fungsi kawasan berdasarkan data yang terdapat pada peta tematik fungsi kawasan dari Direktorat Jenderal Planologi Kehutanan dan Tata Lingkungan Kementerian Lingkungan Hidup dan Kehutanan dan diperoleh dari BPDASHL Batanghari. Data dalam dan luar kawasan hutan adalah penggolongan yang dilakukan terhadap jenis fungsi kawasan berdasarkan kewenangan Pemerintah, terkait tugas dan fungsinya dalam mengelola kawasan hutan. Fungsi kawasan dan keberadaan dalam atau luar kawasan hutan dapat dilihat pada Tabel 4. 
Jurnal Belantara Vol. 4, No 2, Agustus 2021 (127-139)

Tabel 4. Fungsi kawasan dan data dalam atau luar kawasan hutan

Table 4. Area function and data inside or outside the forest area

\begin{tabular}{cll}
\hline Nomor & \multicolumn{1}{c}{ Fungsi Kawasan } & Dalam atau Luar Kawasan \\
\hline 1. & Hutan Lindung & \\
2. & Hutan Konservasi & \\
3. & Hutan Produksi & \\
4. & Hutan Produksi Terbatas & \\
5. & Hutan Produksi Konversi & \\
6. & Taman Wisata Alam Darat & \\
7. & Kawasan Suaka Alam & Dalam Kawasan Hutan \\
8. & Suaka Margasatwa Laut & \\
9. & Cagar Alam Darat & \\
10. & Taman Hutan Raya & \\
11. & Kawasan Pelestarian Alam & \\
12. & Kawasan Suaka Alam dan Wisata Darat & \\
13. & Ka.wasan Suaka Alam dan Wisata Laut & \\
14. & Taman Buru & \\
15. & Taman Wisata Alam Laut & \\
16. & Cagar Alam Laut & \\
17. & Suaka Margasatwa Darat & Luar Kawasan Hutan \\
18. & Taman Nasional Darat & Tubuh Air \\
19. & Taman Nasional Laut & \\
\hline 20. & Areal Penggunaan Lain & \\
\hline 21. & Tubuh Air & \\
\hline
\end{tabular}

Sumber :Perdirjen PDASHL Nomor P.3/PDASHL/SET/KUM.1/7/2018

\section{Analisis Tingkat Kekritisan Lahan}

Lahan kritis terbagi dalam 5 kelas tingkatan yaitu : Tidak Kritis (TK), Potensial Kritis (PK), Agak Kritis (AK), Kritis (K) dan Sangat Kritis (SK). Analisis tingkat kekritisan lahan terbagi dalam beberapa tahapan. Tahapan pertama diawali dengan menumpangtindihkan (overlay) Peta Penutupan Lahan dengan Peta Erosi yang menghasilkan Peta Overlay 1. Hasil overlay selanjutnya di-matching-kan dengan nilai pada Tabel 5 untuk mengetahui jenis tutupan lahan dan masing-masing kelas rawan erosi. Nilai skor terkecil (20) dan yang terbesar (100) memiliki range (80) dibagi manjadi 5 kelas dan nilai jarak perkelas adalah 16 (Tabel 6)

Tabel 5. Skor penutupan lahan dan erosi

Table 5. Land cover and erosion score

\begin{tabular}{|c|c|c|c|c|c|}
\hline \multirow[b]{2}{*}{ Penutupan Lahan (Skor) } & \multicolumn{5}{|c|}{ Rawan Erosi (ton/ha/thn) } \\
\hline & $\begin{array}{c}<15 \\
\text { (Skor 8) }\end{array}$ & $\begin{array}{l}>15-60 \\
\text { (Skor 16) }\end{array}$ & $\begin{array}{l}>60-180 \\
\text { (Skor 24) }\end{array}$ & $\begin{array}{r}180-480 \\
\text { (Skor 32) }\end{array}$ & $\begin{array}{c}>480 \text { (Skor } \\
40)\end{array}$ \\
\hline Rawa (12) & & & & & \\
\hline $\begin{array}{l}\text { Savana (12) } \\
\text { Hutan primer (12) }\end{array}$ & 20 & 28 & 36 & 44 & 52 \\
\hline $\begin{array}{l}\text { Hutan sekunder ( } 24) \\
\text { Hutan tanaman (24) }\end{array}$ & 32 & 40 & 48 & 56 & 64 \\
\hline Perkebunan (36) & 44 & 52 & 60 & 78 & 76 \\
\hline $\begin{array}{l}\text { Semak/ belukar (48) } \\
\text { Pertanian lahan kering (48) }\end{array}$ & 56 & 64 & 72 & 80 & 88 \\
\hline $\begin{array}{l}\text { Tanah terbuka (Skor 60) } \\
\text { Pertambangan }\end{array}$ & 68 & 76 & 84 & 92 & 100 \\
\hline
\end{tabular}

[132] This work is licensed under a Creative Commons Attribution 4.0 International License 
Tabel 6. Skor kekritisan lahan

Table 6. Land criticality score

\begin{tabular}{cc}
\hline Nomor & Skor_Kritis \\
\hline 1 & $20-36$ \\
2 & $36-52$ \\
3 & $52-68$ \\
4 & $68-84$ \\
5 & $84-100$ \\
\hline erdirjen PDASHL Nomor P.3/PDASHL/SET/KUM.1/7/2018
\end{tabular}

Tahapan selanjutnya yaitu menumpangtindihkan Peta Overlay 1 dengan Peta Lereng dan analisa dalam kawasan hutan yang dapat dilihat pada Tabel 7, tahapan ini menghasilkan Peta Overlay 2 yaitu Peta Lahan Kritis.

Tabel 7. Skor analisa lahan kritis di dalam kawasan hutan

Table 7. Critical land analysis score in forest area

\begin{tabular}{|c|c|c|c|c|c|}
\hline \multirow{2}{*}{$\begin{array}{l}\text { Lereng } \\
(\%)\end{array}$} & \multicolumn{5}{|c|}{ Skor kekritisan } \\
\hline & $0-36$ & $>36-52$ & $>52-68$ & $>68-84$ & $\begin{array}{c}>84- \\
100\end{array}$ \\
\hline $0-8$ & TK & TK & PK & $\mathrm{K}$ & SK \\
\hline$>8-15$ & TK & PK & AK & $\mathrm{K}$ & SK \\
\hline$>15-25$ & PK & AK & AK & $\mathrm{K}$ & SK \\
\hline$>25-40$ & AK & AK & AK & $\mathrm{K}$ & SK \\
\hline$>40$ & AK & AK & AK & $\mathrm{K}$ & SK \\
\hline
\end{tabular}

Sumber: Perdirjen BPDASHL Nomor P.3/PDASHL/SET/KUM.1/7/2018

Keterangan: TK (Tidak Kritis), PK (Potensial Kritis), AK (Agak Kritis), K (Kritis) dan SK (Sangat Kritis)

\section{Interpretasi Data}

Peta lahan kritis yang dihasilkan selanjutnya diinterpretasi dan dideskripsikan secara kualitatif dan kuantitatif. Pendeskripsian secara kualitatif yaitu untuk mengetahui sebaran dan tingkat kekritisan lahan. Sedangkan analisis secara kuantitatif untuk mengetahui luasan dan persentase masing-masing kelas kekritisan lahan. Selanjutnya diuraikan dan dijelaskan faktorfaktor penyebab kekritisan lahan dari parameter-parameter lahan kritis.

\section{HASIL DAN PEMBAHASAN}

\section{Penutupan Lahan di KPHP Unit XII Batanghari}

Berdasarkan hasil interpretasi dan klasifikasi tutupan lahan pada Citra Landsat 8 kanal RGB 654, dideteksi warna hijau gelap yaitu hutan sekunder, hijau tua pudar yaitu perkebunan, hijau tua yaitu hutan tanaman dan hijau kekuningan yaitu semak belukar, lahan terbuka berwarna merah muda dan berwarna keunguan. Badan air di lapangan tidak terdeteksi di citra karena hanya memiliki luasan kecil. Indentifikasi tutupan lahan dan groundcheck dapat dilihat pada Tabel 8. 
Tabel 8. Warna tiap kelas tutupan lahan dan foto lapangan

Table 8. Color of each land cover class and field photos

\begin{tabular}{ccc}
\hline Tutupan Lahan & Wana pada citra & Foto Lapangan \\
\hline Hutan Sekunder & & \\
\hline Hutan Tanaman & & \\
\hline Perkebunan & & \\
\hline Semak Belukar & & \\
\hline Lahan Terbuka & & \\
\hline
\end{tabular}

Sumber: Dokumentasi penelitian, 2020

Hasil analisis menunjukkan bahwa perkebunan dan hutan sekunder merupakan tutupan lahan yang terluas, masing-masing seluas 31.873 ha $(39,28 \%)$ dan 30.934 ha $(38,12 \%)$. Tutupan lahan lainnya berupa hutan tanaman seluas 2.886 ha $(3,56 \%)$, semak belukar seluas 5.035 ha $(6,20 \%)$ dan lahan terbuka seluas 10.420 ha $(12,84 \%)$. Hutan sekunder dan hutan tanaman diberi skor 24, perkebunan diberi skor 36, semak belukar diberi skor 48 dan lahan terbuka skor 60 .

Tutupan lahan hutan sekunder terdapat pada kawasan Hutan Produksi Tetap (HP) dan Hutan Produksi Terbatas (HPT). Hutan sekunder yang ditemukan memiliki ciri hamparan yang didominasi oleh pohon-pohon kehutanan, jenis dan umur pohon beragam, struktur hutan yaitu semai, pancang, tiang dan pohon. Hutan sekunder tersebar diseluruh wilayah KPHP Unit XII Batanghari. Tutupan lahan hutan tanaman hanya terdapat pada wilayah HTI dengan tegakan sengon, akasia dan eucalyptus. Tutupan lahan perkebunan ditemukan hampir disemua bagian KPHP Unit XII Batanghari, yaitu pada kawasan HP (pada Hutan Tanaman Rakyat, Hutan Tanaman Industri dan Hutan Desa) dan kawasan HPT (pada restorasi ekosistem). Tanaman perkebunan yang dibudidayakan yaitu karet dan kelapa sawit. Tutupan lahan semak belukar dapat dijumpai di seluruh wilayah KPHP Unit XII Batanghari kecuali pada Hutan Desa. Semak belukar merupakan areal bekas terbakar dan terbuka yang telah mengalami suksesi alami. Tutupan lahan jenis lahan terbuka yang ditemukan merupakan lahan bekas terbakar dan areal penanaman baru untuk hutan tanaman, sengon, akasia dan eucalyptus. Lahan terbuka memiliki resiko menjadi lahan kritis sangat besar, karena bagian atas tanah tidak memiliki pelindung berupa vegetasi tanaman. 


\section{Tingkat Erosi di KPHP Unit XII Batanghari}

Berdasarkan data dari BPDASHL Batanghari, sebesar 69,3 \% (56.235 ha) kawasan KPHP Unit XII Batanghari termasuk dalam kelas erosi ringan yaitu $<15$ ton/ha/thn. Kelas rawan erosi sangat berat dengan besar erosi $>480$ ton/ha/thn tidak ditemukan di kawasan KPHP Unit XII Batanghari (Tabel 9). Tutupan lahan perkebunan memiliki tingkat erosi yang cukup tinggi yaitu mayoritas pada tingkat $>180-480$ ton/ha/thn. Kondisi tutupan lahan pada perkebunan sawit yang masih berumur muda berdampak pada lahan yang tidak tertutup tajuk dengan sempurna sehingga tanah rentan erosi. Berbeda dengan hutan sekunder dan hutan tanaman yang tertutup tajuk dan serasah sehingga air hujan yang jatuh tidak langsung merusak tanah.

Tabel 9. Luas tiap kelas dan skor rawan erosi

Table 9. The area of each class and erosion-prone scores

\begin{tabular}{cccc}
\hline \multirow{2}{*}{$\begin{array}{c}\text { Kelas Erosi } \\
\text { (ton/ha/thn) }\end{array}$} & Skor & \multicolumn{2}{c}{ Luas } \\
\cline { 3 - 4 } & & & ha \\
\hline$<15$ & 8 & 56.235 & 69,30 \\
$15-60$ & 16 & 9.017 & 11,11 \\
$60-180$ & 24 & 9.166 & 11,30 \\
$180-480$ & 32 & 6.731 & 8,29 \\
$>480$ & 40 & - & - \\
\hline Jumlah & & 81.149 & 100 \\
\hline
\end{tabular}

Sumber: Hasil analisis, 2020

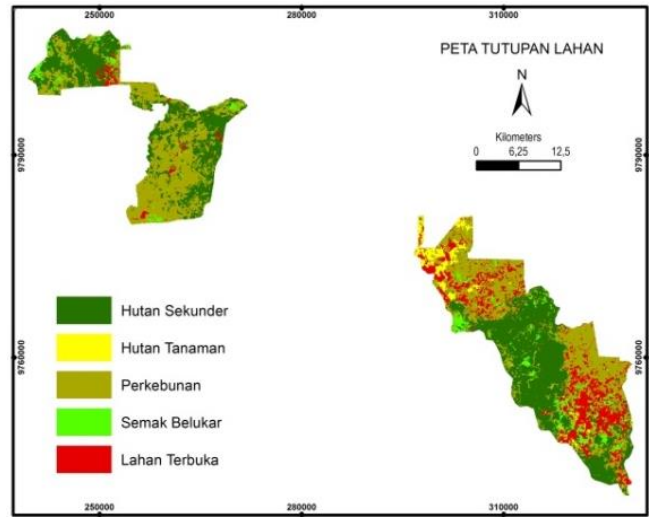

Gambar 1. Peta Tutupan Lahan

Figure1. Landcover map

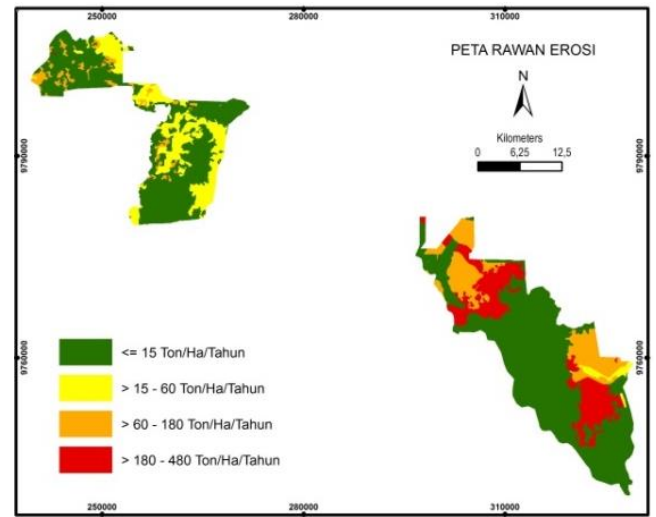

Gambar 2. Peta Rawan Erosi

Figure 2. Erosion prone map 


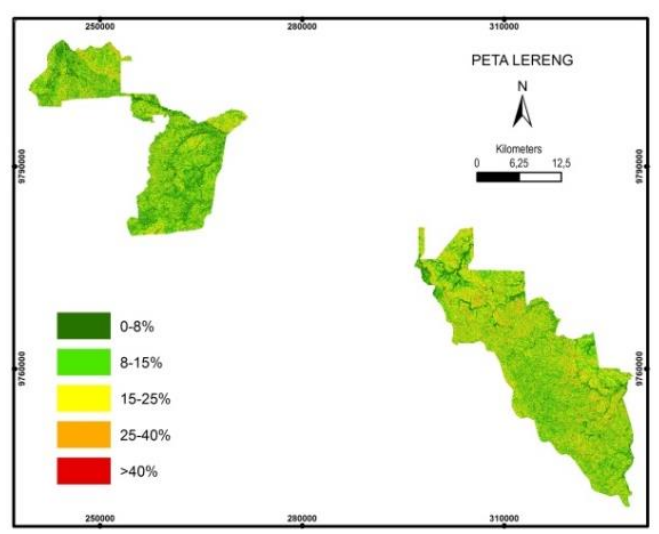

Gambar 3. Peta Lereng

Figure 3. Slope map

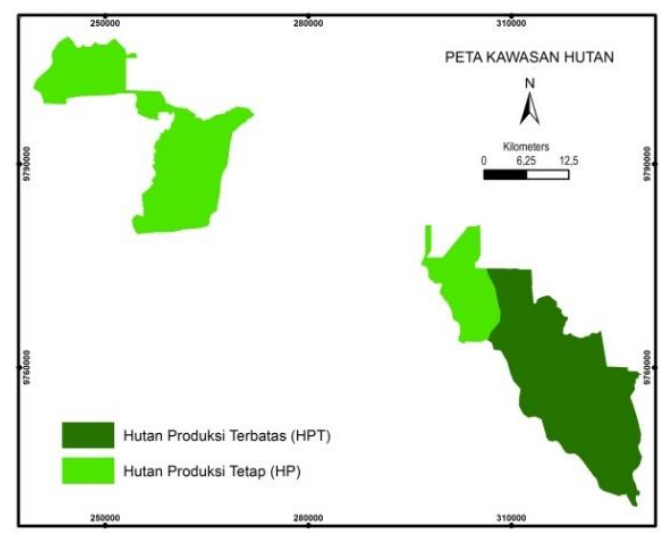

Gambar 4. Peta Kawasan Hutan

Figure 4. Forest area map

\section{Kelerengan di KPHP Unit XII Batanghari}

Topografi lahan KPHP Unit XII Batanghari beragam. Hasil analisis peta lereng dan pengecekan lapangan, kelas lereng $8-15 \%$ merupakan yang terluas yaitu 27.845 ha $(34,31 \%)$ dengan topografi berombak hingga bergelombang. Lereng dengan kelas $15-25 \%$ (bergelombang) memiliki luasan 22.658 ha $(27,97 \%)$.Topografi datar hingga landai $(0-8 \%)$ memiliki luas 20.897 ha $(25,76 \%)$. Topografi berbukit hingga pegunungan hanya sebagian kecil ditemukan yaitu seluas 7.730 ha $(9,52 \%)$ dengan kelas lereng $25-40 \%$ dan seluas 2.019 ha $(2,49 \%)$ dengan lereng $>40 \%$.

\section{Fungsi Kawasan di KPHP Unit XII Batanghari}

Analisis lahan kritis berdasarkan fungsi kawasan yang berada di dalam atau di luar kawasan hutan. KPHP Unit XII Batanghari merupakan unit pengelolaan hutan di tingkat tapak yang wilayah kerjanya masuk kedalam kawasan hutan. Fungsi kawasan yang masuk ke dalam kawasan hutan sangat menentukan proses analisis yang memiliki skor yang dibandingkan dengan kelerengan.

\section{Tingkat Kekritisan Lahan KPHP Unit XII Batanghari}

Hasil analisis sebaran dan tingkat kekritisan lahan di KPHP Unit XII Batanghari disajikan pada Tabel 10 dan Gambar 5.

Tabel 10. Sebaran tingkat kekritisan lahan di KPHP Unit XII Batanghari

Table 10. Distribution of land criticality level at KPHP Unit XII Batanghari

\begin{tabular}{lrr}
\multirow{2}{*}{ Tingkat Kekritisan Lahan } & \multicolumn{2}{c}{ Luas } \\
\cline { 2 - 3 } & \multicolumn{1}{c}{ ha } & \multicolumn{1}{c}{$\%$} \\
\hline Tidak Kritis & 24.844 & 30,62 \\
Potensial Kritis & 23.074 & 28,43 \\
Agak Kritis & 26.024 & 32,07 \\
Kritis & 3.599 & 4,43 \\
Sangat Kritis & 3.609 & 4,45 \\
\hline \multicolumn{1}{c}{ Jumlah } & 81.150 & 100 \\
\hline
\end{tabular}

Sumber: Hasil analisis, 2020 


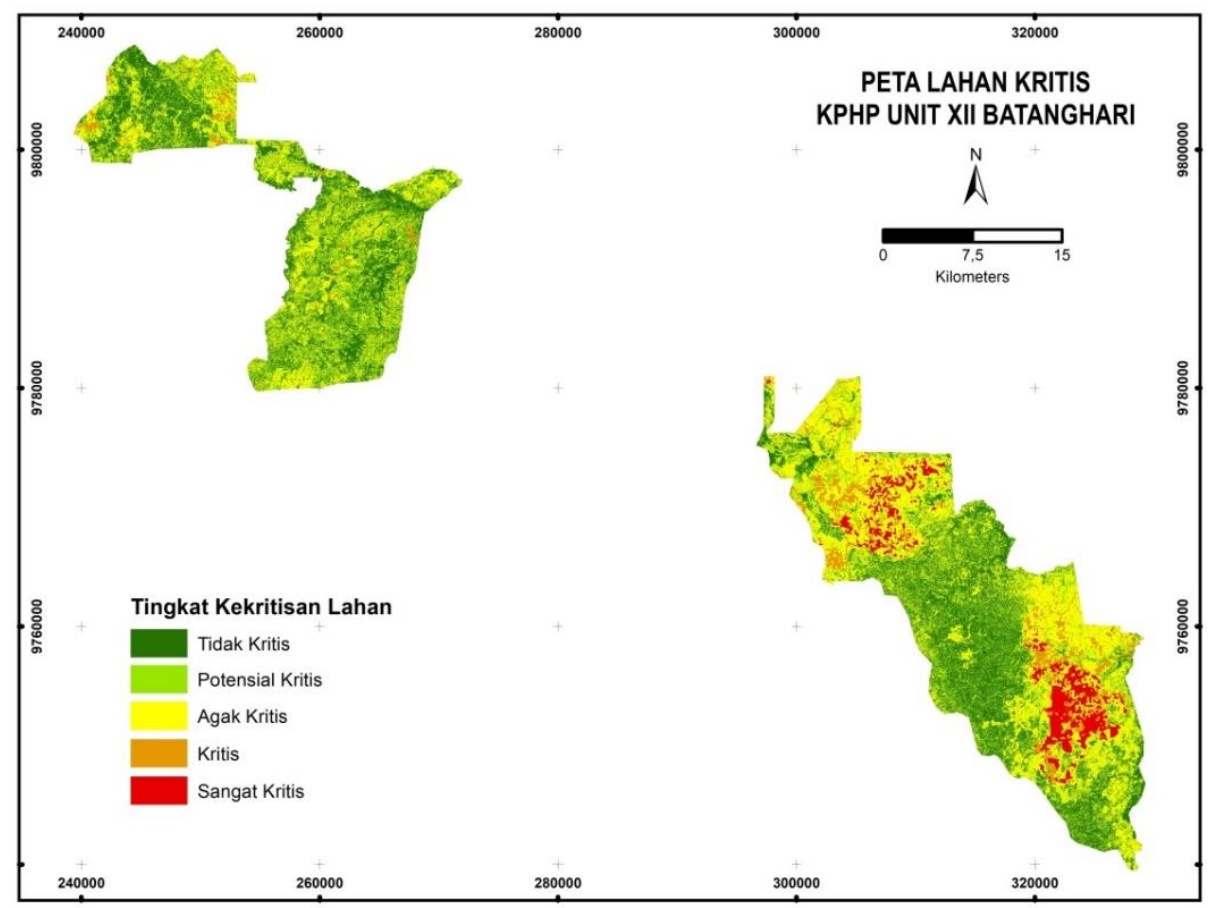

Gambar 5. Peta Lahan Kritis KPHP Unit XII Batanghari

Figure 5. Critical land map at KPHP Unit XII Batanghari

Secara umum, kondisi lahan di KPHP Unit XII Batanghari didominasi oleh tingkat kekritisan agak kritis sebesar 26.024 ha (32,07\%), baik di wilayah HP maupun HPT. Penutupan lahan pada kelas lahan tersebut yaitu perkebunan, semak belukar dan lahan terbuka. Sebaran lahan dengan tingkat kekritisan tidak kritis dan potensial kritis merupakan sebaran terluas kedua dan ketiga di KPHP Unit XII Batanghari, masing-masing sebesar 24.844 ha $(30,62 \%)$ dan 23.073 ha (28,43\%). Penutupan lahan pada lahan tidak kritis dan potensial kritis yaitu hutan sekunder dan perkebunan. Faktor kelas rawan erosi menyebabkan perbedaan hasil tingkat kekritisan di penutupan lahan yang sama.

Hasil analisis mengindikasikan adanya lahan dengan tingkat kritis dan sangat kritis dengan luas masing-masing yaitu 3.599 ha $(4,43 \%)$ dan 3.609 ha $(4,45 \%)$. Penutupan lahan di kedua kelas tersebut yaitu lahan terbuka, namun pada masing-masing berbeda tingkat kelas rawan erosi. Lahan tingkat sangat kritis memiliki tingkat erosi tinggi dan lahan tingkat kritis memiliki tingkat erosi sedang. Penutupan lahan terbuka dikarenakan lahan bekas terbakar dan areal pascapanen HTI.

Lahan agak kritis berpotensi menjadi lahan kritis bahkan sangat kritis jika pengelolaan lahan tidak dilakukan dengan optimal, terutama dalam menjaga kondisi tutupan lahan. Pengelolaan dan perbaikan lahan kritis dapat dilakukan dengan perbaikan tutupan lahan, yaitu merubah lahan terbuka dan semak belukar menjadi lahan berhutan atau lahan bervegetasi. Perbaikan tutupan lahan melalui kegiatan rehabilitasi pada akhirnya mampu menekan laju erosi dan berdampak pada peningkatan kualitas lahan.

\section{KESIMPULAN}

Analisis lahan kritis yang berpedoman pada Perdirjen BPDASHL Nomor P.3/PDASHL/SET/KUM.1/7/2018, parameter tutupan lahan memiliki bobot tertinggi yaitu skor 60. Tutupan lahan tanah terbuka merupakan penyebab utama klasifikasi tingkat kekritisan lahan menjadi sangat kritis seluas 3.609 ha $(4,45 \%)$ dan kritis seluas 3.599 ha $(4,43)$ di KPHP Unit XII Batanghari. Tingkat kekritisan lahan di KPHP Unit XII Batanghari termasuk baik, dimana seluas 73.942 ha atau $91,12 \%$ dari luas kawasan merupakan lahan dengan tingkat kekritisan agak kritis, potensial kritis dan tidak kritis. 


\section{UCAPAN TERIMA KASIH}

Ucapan terimakasih penulis sampaikan kepada Universitas Jambi yang telah memfasilitasi terlaksananya kegiatan penelitian ini melalui sumber pendanaan PNBP Jurusan Kehutanan Fakultas Pertanian Unja Tahun Anggaran 2020. Selanjutnya terima kasih kepada instansi terkait yaitu BPDASHL Batanghari dan KPHP Unit XII Batanghari yang telah membantu terlaksananya kegiatan penelitian ini.

\section{DAFTAR PUSTAKA}

Achmad, E., Hamzah, Albayudi. 2020. Analisis Perubahan Tutupan Lahan Pada Zonasi Pengelolaan Taman Nasional Bukit Tiga Puluh Menggunakan Citra Landsat. Jurnal Hutan Tropis, 8(2), 172-184. DOI: http://dx.doi.org/10.20527/jht.v8i2.9047

Anasiru, R.H. 2016. Analisis spasial dalam klasifikasi lahan kritis di kawasan Sub-DAS Langge Gorontalo. Informatika Pertanian, 25(2), 261-272.

Auliana, Ridwan, I. \& Nurlina. 2017. Analisis tingkat kekritisan lahan di DAS Tabunio Kabupaten Tanah Laut. Positron, http://dx.doi.org/10.26418/positron.v7i2.18671.

Kebede, Y.S., Endalamaw, N.T., Sinshaw, B.G. \& Atinkut, H.B. 2021. Modeling soil erosion using RUSLE and GIS at watershed level in the upper beles, Ethiopia. Environmental Challenges, 2(2021). https://doi.org/10.1016/j.envc.2020.100009

Keputusan Menteri Lingkungan Hidup dan Kehutanan Nomor : SK.306/MENLHK/DAS.0/7/2018 Tentang Penetapan Lahan Kritis Nasional.

Kementerian Lingkungan Hidup dan Kehutanan. 2019. Deforestasi Indonesia Tahun 2017-2018. Direktorat Inventarisasi dan Pemanfaatan Sumber Daya Hutan. Direktorat Jenderal Planologi Kehutanan dan Tata Lingkungan. Kementerian Lingkungan Hidup dan Kehutanan. Jakarta.

Kementerian Lingkungan Hidup dan Kehutanan. 2018. Peraturan Direktur Jenderal Pengendalian Daerah Aliran Sungai dan Hutan Lindung Nomor P.3/Pdashl/Set/Kum.1/7/2018.

KPHP Unit XII Batang Hari. 2016. Dokumen Tata Hutan 2016, RPHJP KPHP Unit XII Batang Hari.

Kusumandari, A. \& Nugroho, P. 2015. Land capability analysis based on hydrology and soil characteristics for watershed rehabilitation. Procedia Environmental Sciences, 28(2015), 142-147. doi: 10.1016/j.proenv.2015.07.020.

Majid, M. \& Mir, B.A. Landfill site selection using GIS based multi criteria evaluation technique. A case study of Srinagar city, India. Environmental Challenges, 3(2021). https://doi.org/10.1016/j.envc.2021.100031.

Makalalag, M.F.M., Takumansang, E.D \& Tarore, R.C. 2020. Analisis spasial sebaran lahan kritis di Kawasan Danau Mooat Kabupaten Bolaang Mongondow Timur. Perencanaan Wilayah dan Kota, 7(3), 313-324.

Mulyadi, A. \& Jupri. 2016. Kajian lahan kritis Sub Daerah Aliran Ci Keruh di Kawasan Cekungan Bandung. Prosiding Seminar Nasional Geografi UMS 2016, Upaya Pengurangan Risiko Bencana Terkait Perubahan Iklim.

Nasihin, I., Prasetyo, L.B., Kartono, A.P. \& Kosmaryandi, N. 2016. Land cover change in Kuningan District during 1994 - 2015. Procedia Environmental Sciences ,33(2016), 428 435. doi: 10.1016/j.proenv.2016.03.093.

Nugroho, S.P. \& Prayogo, T. 2008. Penerapan SIG untuk penyusunan dan analisis lahan kritis pada satuan wilayah Pengelolaan DAS Agam Kuantan, Provinsi Sumatera Barat. Teknik Lingkungan, 9(2), 130-140. 
Pijl, A., Quarella, E., Vogel, T.A., D’Agostino, V. \& Tarolli, P. 2021. Remote sensing vs. fieldbased monitoring of agricultural terrace degradation. International Soil and Water Conservation Research, 9(2021), 1-10. https://doi.org/10.1016/j.iswcr.2020.09.001.

Prabandaru, L.H., Nugraha, A.L. \& Sumkmono, A. 2016. Pemetaan tingkat lahan kritis Kabupaten Wonosobo dengan penginderaan jauh dan Sistem Informasi Geografis. Geodesi Undip, 5(4), 65-72.

Ramayanti, L.A., Yuwono, B.D. \& Awaluddin, M. 2015. Pemetaan tingkat lahan kritis dengan menggunakan penginderaan jauh dan Sistem Informasi Geografi (Studi Kasus : Kabupaten Blora). Geodesi Undip, 4(2), 200-207.

Rosyada, M., Prasetyo, Y. \& Hani'ah. 2015. Penentuan tingkat lahan kritis menggunakan metode pembobotan dan algoritma NDVI (Studi Kasus: Sub DAS Garang Hulu). Geodesi Undip, 4(1), 85-94.

Ruhama, A., Numba, S. \& Saida. 2020. Analisis lahan kritis dan arahan penggunaan lahan pada Sub Daerah Aliran Sungai Binanga Lantang di Sulawesi Selatan. Agrotek, 4(1), 3752.

Suriani, Mey, D. \& Saleh, F. 2019. Pemetaan lahan kritis dengan metode Multi Criteria Evaluation di Sub DAS Amohalo. Geografi Aplikasi dan Teknologi, 3(1), 7-16.

Sunartomo, A.F. 2011. Inventarisasi dan sebaran lahan kritis di Kabupaten Situbondo. J-SEP, $5(1), 12-22$.

Suntoro, M.A., Astiani, D. \& Ekyastuti, W. 2019. Analisis lahan kritis dan arahan lahan dalam pengembangan wilayah pada SubDAS di Kabupaten Kayong Utara menggunakan teknik penginderaan jauh dan Sistem Informasi Geografis. Tengkawang, 9(1), 14-26.

Tavana, M., Liu, W., Elmore, P., Petry, P.E. \& Bourgeois, B.S. 2016. A practical taxonomy of methods and literature for managing uncertain spatial data in geographic information systems. Measurement ,81(2016), 123-162. http://dx.doi.org/10.1016/i.measurement.2015.12.007. 